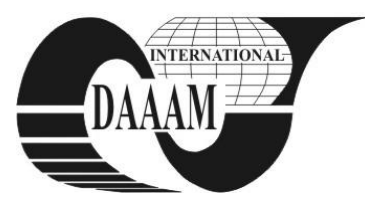

Annals of DAAAM for 2011 \& Proceedings of the 22nd International DAAAM Symposium, Volume 22, No. 1, ISSN 1726-9679 ISBN 978-3-901509-83-4, Editor B. Katalinic, Published by DAAAM International, Vienna, Austria, EU, 2011 Make Harmony between Technology and Nature, and Your Mind will Fly Free as a Bird Annals \& Proceedings of DAAAM International 2011

\title{
REMOTE MEASUREMENTS OF VARIABLE TOPOLOGY SYSTEM
}

\author{
VINCE, T[ibor] \& MOLNAR, J[an]
}

\begin{abstract}
The article presents possibility of remote measurement for education purposes. System developed for remote measurements of electrical circuit via the Internet allows assembling electrical circuits remotely. Students are able to design electrical circuit using the circuit elements; they can select elements from the defined set of electrical elements and create connections between them. Then is the circuit proposal assembled using real electrical elements. Students are able to control source voltage levels and read the values on measure devices. Present system state can be used for education or also for commercial purpose of electrical circuit measurements.
\end{abstract}

Key words: remote measurement, variable topology, electrical circuit

\section{INTRODUCTION}

Academic area is strongly influenced by progress in innovation processes and specific research projects outcomes. Regarding the electronic and electrical engineering, we have been facing with problems such as teaching students with reduced means, limited time and lack of teaching staff or in very broad range. These problems we try to solve in an efficient way. In particular, the main scope of our activity is oriented on the teaching process in the field of electrical and electronic measurements, on research projects that are carried out mainly aiming to provide strong theoretical educational background using hypertexts, practical exercises, examples of image and/or signal processing, virtual instrumentation, and simulations. The state-of-the-art critical points arise mainly in laboratory and experimental lessons: however, there has been an increase in number of students and therefore also in instrument costs and their complexity, there has been a decrease in budget for laboratory technicians and equipment. This trend has emphasized the need for laboratories remotely accessible via Internet. However, only a few of the current applications allow a real instrument to be accessed by the user in order to effectively perform a measurement.

In the concept we are introducing in the paper, a remote student (Client) must have compatible software environment that is run on the remote laboratory computer (Server). Thus a specific product, a certain platform, and the related costs are imposed to the student. Moreover, some Client-Server applications currently used in remote teaching fields do not allow a measurement application to be concurrently accessed by more than one user. Teaching the measurement methodology requires, more than other topics, a huge practical experience in order to assure a good knowledge transfer from teacher to the students. Students should achieve such level of practical experience by working in recently up-to-date conditions and instruments. Usually, as a matter of fact, the more sophisticated and expensive measurement instrumentation, the more difficult to keep the technical set up up-to-date. Moreover, there is the necessity to repeat the same experiment many times in order to make all students able to operate the measuring instrumentation on their own. This also makes the technicians shortage even more severe. (Arpaia \& Baccigalupi \& Cennamo \& Daponte, 2000).

Since the Internet is used broadly as a common way that provides teaching and study material in electronic form, the term e-Learning (previously used for defining the teaching methodologies involving electronic aids) has been used as synonym for distance learning via Internet. Internet enables to distribute resources (hardware, software, data and knowledge) worldwide, to reach students or workers in their homes environment with a minimum cost for travelling. The first attempts to utilize e-Learning to fit to clients were based on online self-study system.

\section{ARCHITECTURE OF VML}

Remote Measurements Laboratory (VML) as abbreviated in Slovak language from Vzdialene meracie laboratorium is special system developed by Department of Theoretical Electrical Engineering and Electrical Measurement, Faculty of Electrical Engineering and Informatics at Technical University of Kosice, Slovakia. The entire VML system consists of 3 main parts: client, server and devices table. Architecture of VML is described on following Fig. 1.

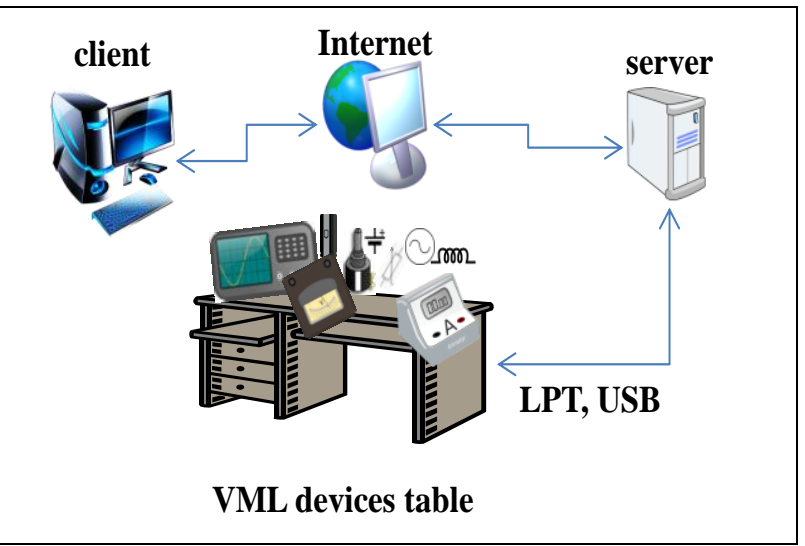

Fig. 1. VML architecture

Devices table consists of electrical components, e.g. resistor, coil, condenser, measurement devices, e.g. voltmeter, ammeter and wattmeter and power supply. All components and devices are connected to specially developed device controlled by the server. Client can connect to the server using client program from anywhere on the world with access point to the Internet. Client creates electric circuit virtually. Then the client sends the circuit scheme to the server. Server sets the devices table according to the circuit scheme via LPT and real electric circuit is created. All measured data from measuring devices are collected on server via USB and sent to the client. User is also able to set voltage value on manageable power supplies. (Kovac \& Vince \& Molnar, 2010) 


\section{DESCRIPTION OF VML FUNCTION}

At the beginning when client starts to work in VLM, he/she connects to the server and asks server for available devices. Server sends a set of devices connected to devices table to the client. A database of server may contain a number of devices possibly connected to the devices table. However, not all the available devices are connected once at the time. Server and parts of devices table are shown on Fig 2.

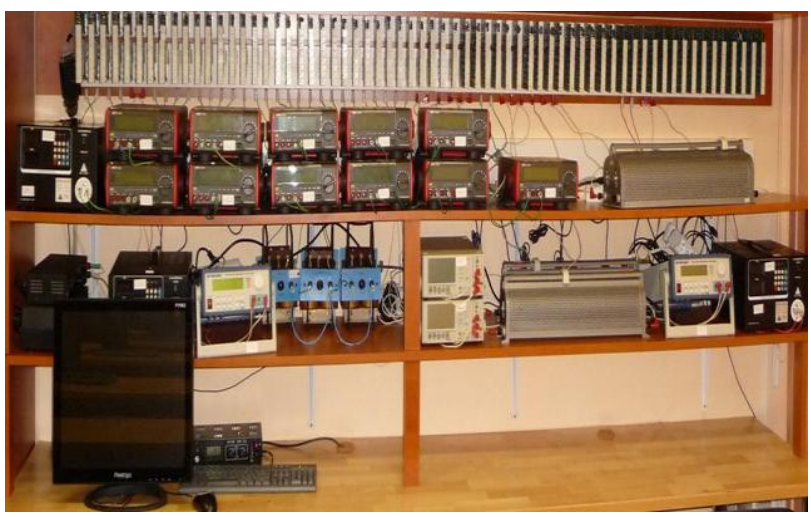

Fig. 2. VML server and devices table

After client receives set of devices, he/she can start to create electric circuit scheme. User is able to use only devices from available set of devices to create the circuit scheme and assemble it using the devices and connecting elements. Client part is shown in Fig. 3.

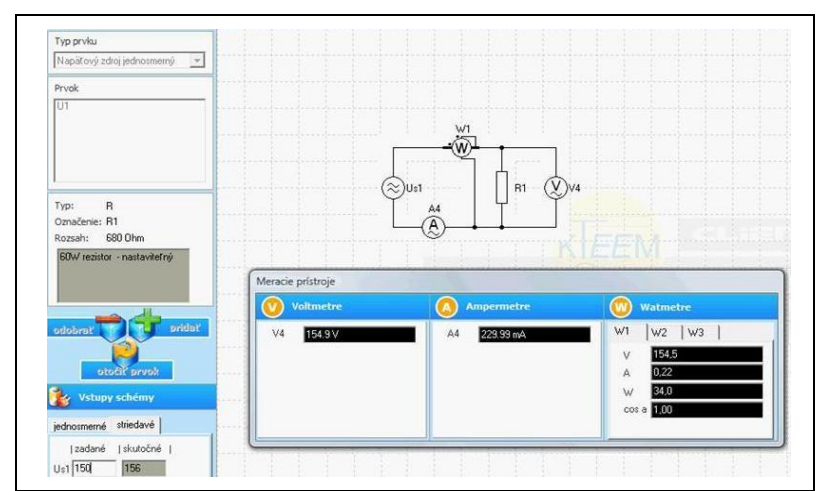

Fig. 3. VML client

After the client completes the virtual electrical circuit, he/she tries to log on VML server. To receive available set of connected devices no authentication is necessary. However, to assemble a real electrical circuit, authentication is required. Only one client at the time may be connected to the server using the authentication. If the server is busy, client has to wait. After successful authentication client sends virtual circuit scheme to the server. Then server sends instruction to the VML devices table and real electric circuit is assembled according to the virtual scheme. Instructions are sent by LPT port. Data from measuring devices are received via USB/RS232 port and forwarded to client. The user can see data from all measuring devices used in the scheme (Fig. 3). The user may also change a voltage of the power supply. The VML system is able to read information of steady state in real time, not the signals displayed on the oscilloscope. Nowadays, VML is configured for education purposes and supports basic course of measuring DC and AC electrical circuits. The technology of VML has much wider application, e.g. remote access to top level measuring devices, automated measuring processes or automated measuring with dynamic topology requirements.

\section{CONCLUSION}

Increasing number of students and instrument costs and decreasing budget for laboratory technicians and equipment result in higher demands on time, costs and lack of technical staff. One of the ways to solve these problems is successfully developed system at our department that allows assembling electric schemes and perform basic measurements remotely. The system based on client/server architecture enables students to create electric scheme from available electric components, connects it to the server, assemble the scheme and perform basic measurements. During the measurement, the user can control the manageable power supply. The biggest advantage is that every student can design own electrical circuit and test the circuit not only in computer simulation. Students may use VML from their home or from any other location with Internet access. There can be also very precise top level measurement set up among the measuring components. Nowadays, there are already some similar measuring remote systems developed. Most of them are capable to measure only static scheme or switch between defined electric schemes. However, VML enables build up schemes dynamically not only those defined before already worldwide. The VML technology is patentpending from 2009. The next step is to extend the technology with implementing the analogue measurement devices or realtime measuring devices e.g. oscilloscope.

\section{ACKNOWLEDGEMENTS}

We support research activities in Slovakia / Project is cofinanced from EU funds. This paper was developed within the Project "Centre of Excellence of the Integrated Research \& Exploitation the Advanced Materials and Technologies in the Automotive Electronics ", ITMS 26220120055
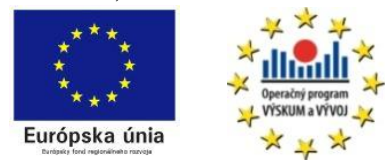

\section{REFERENCES}

Arpaia, P., Baccigalupi, A., Cennamo, F., Daponte, P. (2000): A Measurement Laboratory on Geographic Network for Remote Test Experiments, IEEE transactions on instrumentation and measurement, Vol. 49, No. 5

Canfora D., Daponte P., Rapuano S. (2006): Remotely accessible laboratory for electronic measurement teaching Computer Standards \& Interfaces, Volume 26, Issue 6, Pages 489-499

Kovac, D., Vince, T. , Molnar, J. (2010): Modern Internet Based Production Technology. In: New Trends in Technologies, SCIYO Publisher, Croatia, 2010, 20 pages,ISBN 978-953-307-212-8

Kovacova I., Kovac D. (2010): EMC aspect as important parameter of new technologie. Trends in Technologies: Control, Management, Computational Intelligence and Network Systems. - Rijeka : Sciyo, 2010 P. 305-334. ISBN 978-953-307-213-5

Peretto, L., Rapuano, S., Riccio, M., Bonatti, D (2008): Distance learning of electronic measurements by means of measurement set-up models, Measurement. Vol. 41, no. 3, pp. 274-283

Tomcikova I. (2005): Selected Topics in Electrical Engineering [in slovak], 1st. edition. - Kosice : Elfa, - 2005. - 148 s. ISBN 80-8086-017-3

Simko V., Kovac D., Kovacova I.: Theoretical Electrical Engineering [in slovak], Elfa, - 2002. - 173 s. - ISBN 8089066-27-5 